\title{
Acute myelofibrosis: Report of a case and review of current literature
}

\author{
GREGORY G. MARINO, LCDR, MC, USNR
}

\begin{abstract}
Acute myelofibrosis is a rare hematologic disorder characterized by pancytopenia, normal erythrocyte morphology, extensive marrow fibrosis, and a rapidly fatal clinical course. The etiology of this disease is unknown, but the malignant cell may be of megakaryocytic lineage. Although allogeneic bone marrow transplantation may be effective in achieving complete hematologic remission, optimal management of this rare and often rapidly fatal disease remains to be defined.
\end{abstract}

Acute myelofibrosis is well described in the hematology literature; it is rare and usually results in a rapidly fatal outcome. The cause of this disorder is not known, but recent findings suggest that the disease may arise from abnormal clonal proliferation of an early megakaryocyte precursor. I report a case of acute myelofibrosis and present the proposed pathogenesis of this curious disease and the similarities between it and acute megakaryocytic (FAB [French-American-British] M7) leukemia, the diagnostic features of M7 leukemia, and the therapeutic options for acute myelofibrosis, including the role of allogeneic bone marrow transplantation.

From the department of internal medicine (hematology/ oncology division), and clinical investigation, Naval Hospital, San Diego, Calif.

Reprint requests to LCDR G. C. Marino, MC, USNR, c/o clinical investigation department, Naval Hospital, San Diego, CA 92134-5000.

\section{Report of case}

A 22-year-old man was admitted with anemia, bone pain, and fever. He had been well until 2 months before admission, when headache, night sweats, and daily fevers developed. Two weeks later, malaise, anorexia, and back, shoulder, and lower leg pain developed. At the time of admission, he reported a 40-lb weight loss since the onset of symptoms.

Physical examination revealed an acutely ill patient with a daily afternoon temperature of $38.6^{\circ} \mathrm{C}$ $\left(101.6^{\circ} \mathrm{F}\right)$. Findings of the head and neck examination were normal. The heart and chest examination showed no abnormalities. The abdominal examination showed a palpable spleen tip and a liver edge that was $4 \mathrm{~cm}$ below the right costal margin. The findings of the rectal and genital examinations were normal. No adenopathy was found. Because of pain and weakness, the patient was not able to stand without assistance. No abnormalities were found on neurologic evaluation.

Laboratory studies disclosed the following values: hemoglobin, $10.1 \mathrm{~g} / \mathrm{dL}$; hematocrit $32 \%$, with a rare nucleated $\mathrm{RBC}$ on peripheral blood smear (Fig 1); WBC count, 8000/ $\mathrm{L}$, with a normal differential count; a rare blast form was noted. The red blood cell morphology was normal (Fig 1), and the platelet count was $250,000 / \mu \mathrm{L}$. Bone marrow could not be aspirated, but the bone marrow biopsy revealed necrosis, clusters of undifferentiated blast cells, and greatly increased reticulin (Figs 2 through 4).

The patient did not have a human leukocyte antigen identical sibling and was treated with thioquanine, daunorubicin hydrochloride, and cytarabine. His symptoms promptly improved with resolution of the fever and the bone pain. He gained back some of the weight he had lost and was able to leave the hospital. He returned to his home in Arkansas, but within 3 months of his initial cycle 
Figure 1. High-power view of peripheral blood smear showing a nucleated RBC. Note absence of teardrop-shaped RBCs (Wright's stain, original magnification $\times 100$ ).

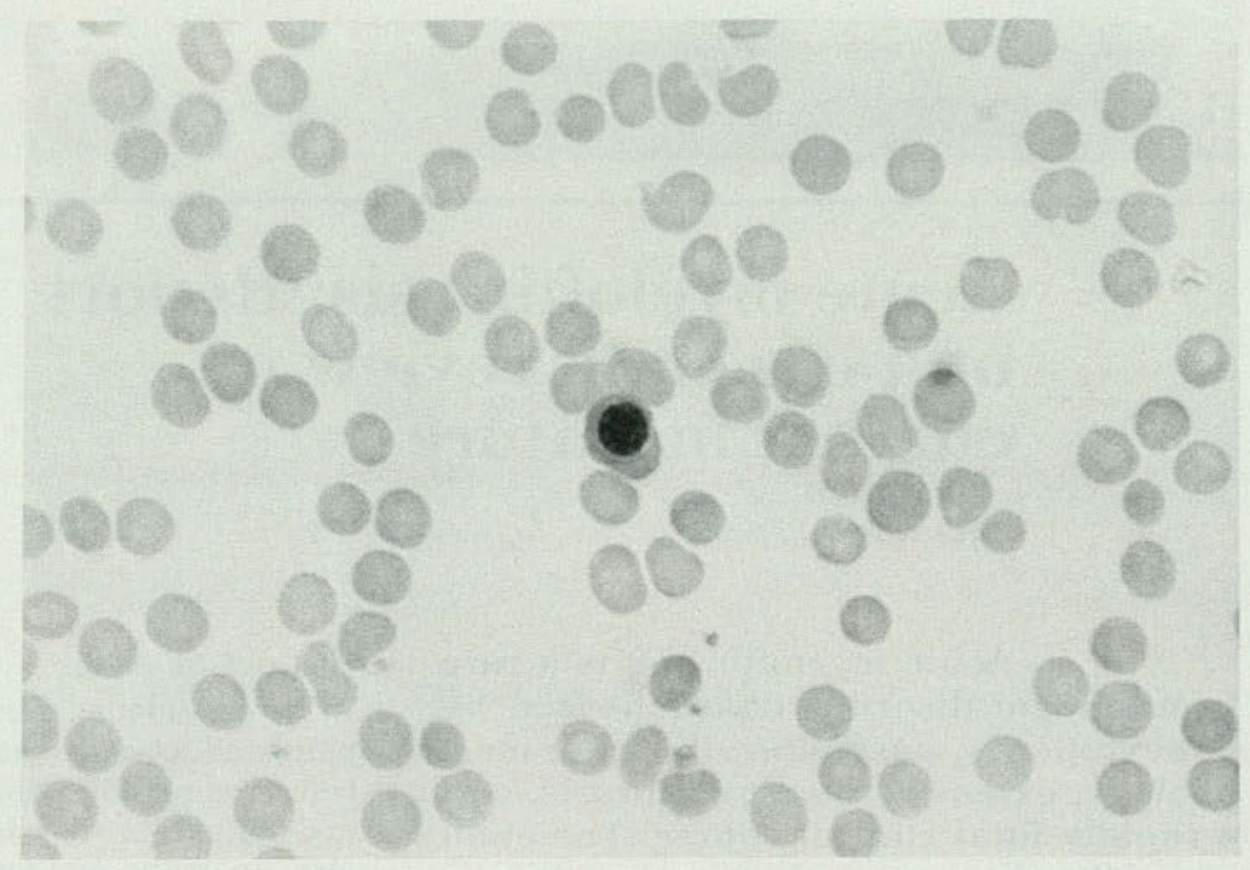

of chemotherapy, malaise, weakness, bone pain, progressive pancytopenia, and myelofibrosis again developed. A second cycle of thioguanine, daunorubicin, and cytarabine was not successful, and the patient died. Postmortem examination was not done.

\section{Discussion}

This case illustrates several of the characteristic features of acute myelofibrosis. The disease has no sex predilection, and the age at presentation ranges from early childhood years through the eighth decade. The patients complain of malaise, fever, and weight loss. Pancytopenia appears to be rapid in onset. Physical findings include absence of organomegaly or only mild hepatosplenomegaly but no significant adenopathy. ${ }^{1,2}$

Peripheral blood findings (Fig 1) include anemia, with absence of or slight anisocytosis and poikilocytosis. Nucleated RBCs can be seen. However, in contrast with chronic myelofibrosis, in which teardrop-shaped red blood cells called dacryocytes are diagnostic findings, dacryocytosis is not found in acute myelofibrosis. ${ }^{3,4}$ The reason for this absence of dacryocytes is not known. It may be that the dacryocytosis seen in chronic myelofibrosis reflects the damage done to the bone marrow microstructure. Bone marrow fibrosis is the hallmark of acute myelofibrosis as well, and pre-

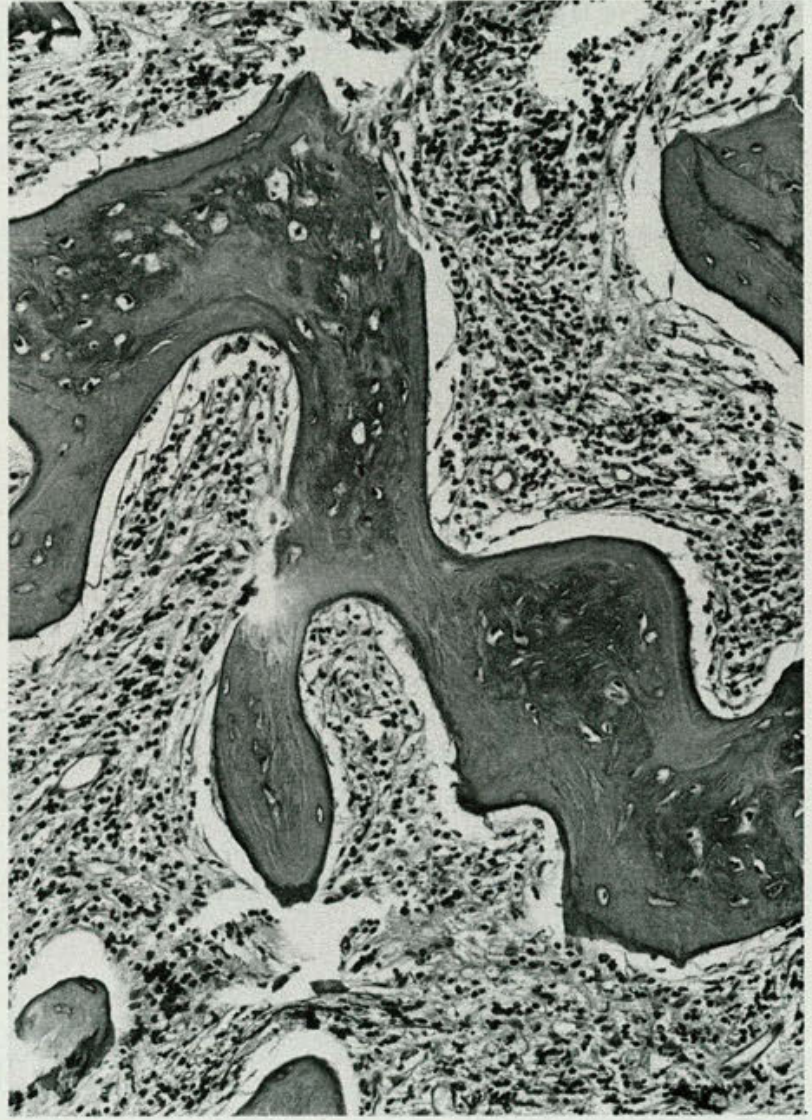

Figure 2. High-power view of marrow biopsy showing a monomorphous population of mononuclear cells and marrow necrosis ( hematoxylin-eosin stain, original magnification $\times 40$ ). 
sumably the degree of marrow microenvironmental disruption present in the two diseases is similar.

Other peripheral blood findings are leukopenia and thrombocytopenia. Monocytopenia is very common, and neutropenia and lymphopenia may be seen as well. ${ }^{4}$ Blast cells, promyelocytes, and myelocytes may also be found on the peripheral blood smear.

Because of the extent of fibrosis, the marrow contents often cannot be aspirated. Biopsy shows a hypercellular marrow and hyperplasia of all three cell lines. ${ }^{4}$ There is a great increase in reticulin (Fig 4), and osteosclerosis, characterized by new bone formation (Fig 3), may also be present.

The clinical course is usually rapid and is marked by refractory and persistent pancytopenia. Survival from the time of onset of

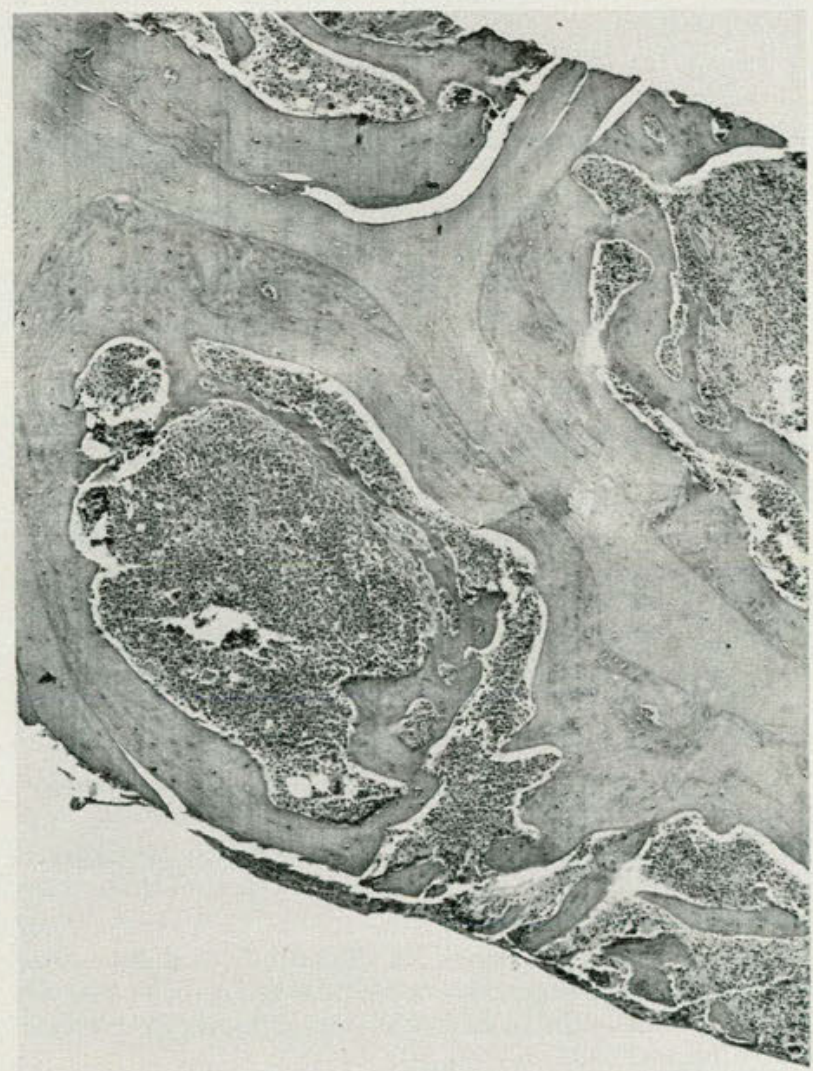

Figure 3. Bone marrow biopsy specimen at low power showing a population of mononuclear cells surrounded by several layers of new bone formation (hematoxylineosin stain, original magnification $\times 10$ ). symptoms ranges from a few weeks to 2 years, with the median survival time being 5 months. ${ }^{1-7}$ The cause of death is usually hemorrhage or infection.

The cause of acute myelofibrosis is not known. The origin of the malignant blast cell has not been clearly established, but it has been proposed that this cell is a megakaryoblast. ${ }^{8-14}$ There is some debate as to whether acute myelofibrosis is a separate and distinct clinical entity or whether it is a variant of acute megakaryocytic leukemia.

In 1985, the French-American-British cooperative study added another category of acute nonlymphocytic leukemia: acute leukemia of megakaryocytic lineage (M7 leukemia). ${ }^{15}$ The diagnosis of M7 leukemia is based on blast cell morphology, cytochemical staining patterns, electron microscopy, immunol-

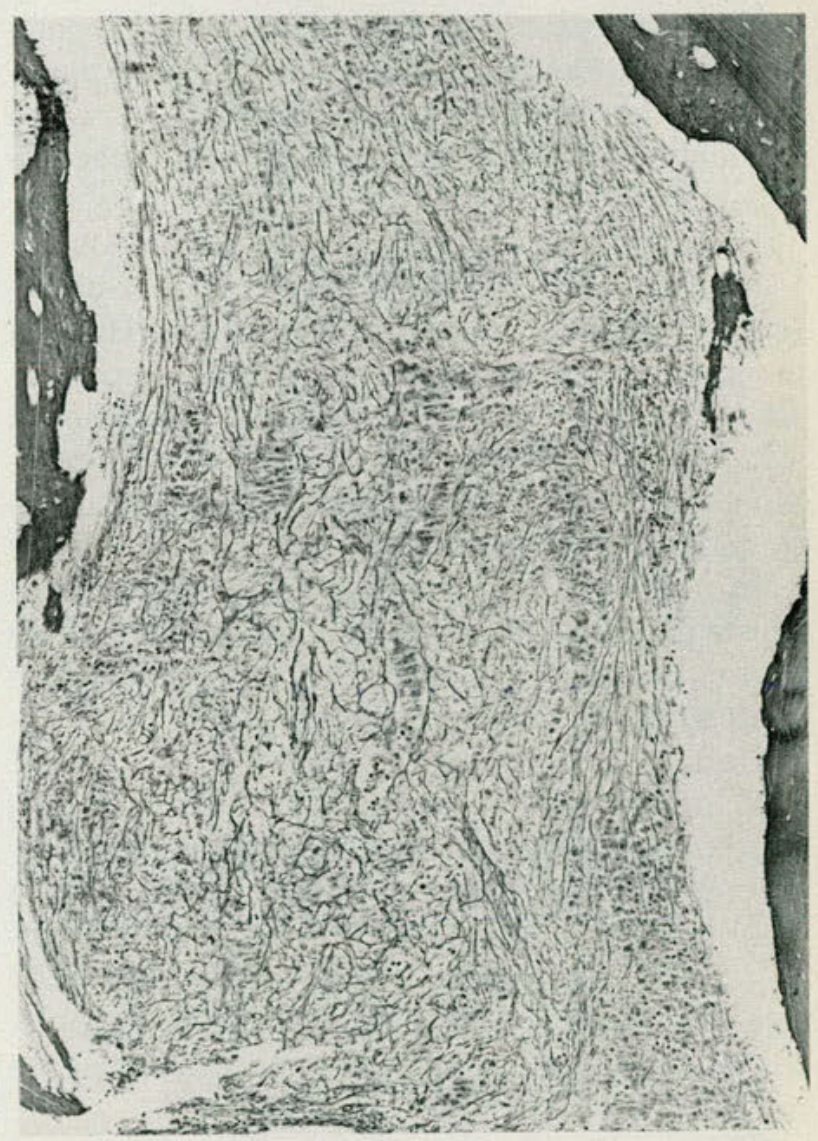

Figure 4. Bone marrow biopsy specimen stained for reticulin (original magnification $\times 10$ ). This high-power view demonstrates the great increase in marrow reticulin that characterizes acute myelofibrosis. 
ogy, and cytogenetics. Morphologically, blast cells are highly pleomorphic, ranging from small round cells with scant amounts of cytoplasm and dense, heavy chromatin to larger blast cells with fine chromatin, with or without granules, and with one to three prominent nucleoli. Blast cells may also have cytoplasmic blebs, around which platelets cluster. Biopsy specimens show marrow fibrosis with increased reticulin.

Cytochemically, M7 leukemia has negative results on Sudan black B and peroxidase staining. The blast cells may be weakly positive in a localized pattern with $\alpha$-naphthylacetate esterase or naphthyl AS-D acetate esterase staining. Because this reaction can be inhibited by the addition of fluoride, the blast cells may be confused with monocytes, which show diffuse cytoplasmic staining. In M7 leukemia, acid phosphatase and periodic acid-Schiff stains may be positive in a localized pattern.

Under the electron microscope, acute megakaryocytic leukemic blast cells are positive for platelet peroxidase activity. This platelet peroxidase reaction has also been described in blast cells from a patient with acute myelofibrosis. ${ }^{12}$

Megakaryoblasts may also be positive when tested with antibodies directed against platelet glycoprotein Ib and glycoprotein IIIa and directed to the glycoprotein IIb/IIIa complex. At this time, the most sensitive monoclonal antibodies for detecting primitive megakaryoblasts are those directed against the glycoprotein IIb/IIIa complex. ${ }^{16}$

In neither M7 leukemia nor acute myelofibrosis are consistent cytogenetic abnormalities found, but in a few cases, abnormalities in the long arm of chromosome 21 have been reported. ${ }^{17}$

Whether or not acute myelofibrosis is a unique and separate disease entity is not resolved. Current data, including the finding of platelet peroxidase activity and positive reactivity of monoclonal antibodies directed against platelet antigens, seem to favor placing acute myelofibrosis as a variant of acute megakaryocytic leukemia.

The reasons for the marrow fibrosis are not fully understood. Several investigators have demonstrated the role of megakaryocytes in the proliferation of bone marrow fibroblasts. ${ }^{18}$
It is proposed that the myelofibrosis seen in acute myelofibrosis is related to megakaryocytic proliferation and is a secondary or reactive phenomenon. In addition, chromosomal studies have shown that, as in other acute leukemias, acute myelofibrosis is a disease of clonal origin and that the fibroblasts are not part of the proliferative process. ${ }^{19}$

Treatment of acute myelofibrosis is disappointing. Standard chemotherapy with anthracyclines and cytarabine has not produced durable remissions in this disease. Allogeneic bone marrow transplantation seems to offer the best prospect for prolonged disease-free survival. Although experience with the procedure has been limited, allogeneic bone marrow transplantation has been shown to produce complete hematologic remission, including total resolution of the marrow fibrosis. ${ }^{20-23}$

1. Lewis SM, Szur L: Malignant myelosclerosis. $\mathrm{Br}$ Med $J$ 1963;116:472-477

2. Truong LD, Salleem A, Schwartz MA: Acute myelofibrosis. Medicine 1984;63:182-187.

3. Rupani M: Acute myelofibrosis. Am J Clin Pathol 1982;77:475478.

4. Bearman RM, Pangalis GA, Rapaport H: Acute ('malignant') myelosclerosis. Cancer 1979;43:279-293.

5. Bergsman KL, Van Slyck EJ: Acute myelofibrosis. Ann Intern Med 1971;74:232-235.

6. Sultan C, Sigaux F, Imbert M, et al: Acute myelodysplasia with myelofibrosis: A report of eight cases. $\mathrm{Br} J$ Haematol 1981;49:11-16.

7. Fabich DR, Raich PC: Acute myelofibrosis. Am J Clin Pathol 1977;67:334-338.

8. Bain BJ, Catovsky D, O'Brien M, et al: Megakaryoblastic leukemia presenting as acute myelofibrosis: A study of four cases with the platelet peroxidase reaction. Blood 1981;58:206-213.

9. Shreeder MT, Prchal JT, Parmley RT: An acute myeloproliferative disorder characterized by myelofibrosis and blast cells that express phenotypic properties associated with multiple hematopoietic lineages. Am J Clin Pathol 1985;83:114-121.

10. Chan WC, Brynes RK, Kim TH, et al: Acute megakaryoblastic leukemia in early childhood. Blood 1983;62:92-98.

11. den Ottolander GJ, te Velde J, Brederoo P, et al: Megakaryoblastic leukemia (acute myelofibrosis): A report of three cases. Br J Haematol 1979;42:9-20.

12. Breton-Gorius JB, Daniel MT, Flandrin G, et al: Fine structure and peroxidase activity of circulating micromegakaryoblasts and platelets in a case of acute myelofibrosis. Br J Haematol 1973;25:331-339.

13. Huang MJ, Li CY, Nicholas WL, et al: Acute leukemia with megakaryocytic differentiation: A study of twelve cases identified immunocytochemically. Blood 1984;64:427-439.

14. Koike T: Megakaryoblastic leukemia: The characterization and identification of megakaryoblasts. Blood 1984;64:683-692. 15. Bennett JM, Catovsky D, Daniel MT, et al: Criteria for the 
The \#1 prescribed allergy in the U.S. and worldwide

\section{NO ANTIHISTAMINE}

OLD OR NEW

\section{IS MORE EFFECTIVE}

Maximum efficacy - proven in 30 double-blind clinical studies ${ }^{1-5}$

Fast onset of action-most patients experience significant relief within 1 hour, ${ }^{6+}$ maximum efficacy in 3-4 hours h** $^{7 *}$

Efficacy maintained with through-the-season use s-10 $^{8}$

Unmatched patient preference- $77 \%$ of patients who started on Seldane and obtained another prescription in the category refilled that prescription with Seldane.

(Based upon a 1986 nationwide study of 640 patient members of prepaid group benefit plans.)

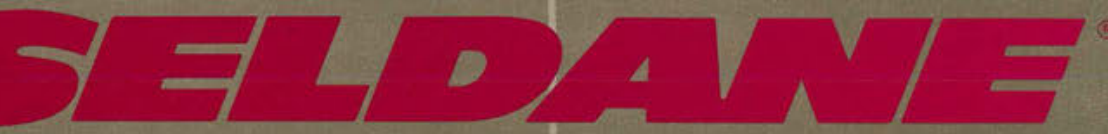

(terfenadine) $60 \mathrm{mg}$ tablets BID

for seasonal allergic rhinitis

The ideal profile for fast, on-the-job relief

Based upon worldwide prescription and distribution information (1986-1988)-data on file. 

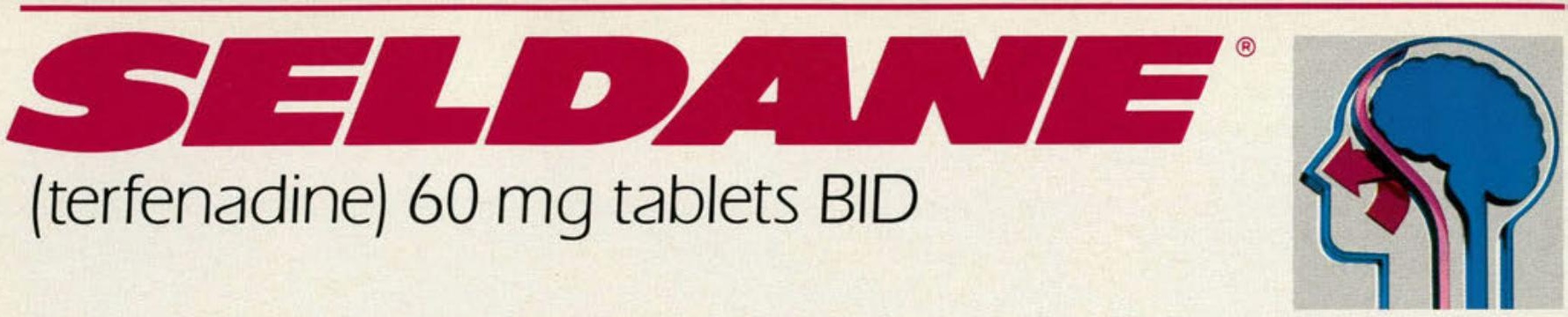

\section{Fast, unsurpassed relief \\ - Efficacy maintained in through-the-season use - B.i.d. dosing for high patient compliance High patient preference Lets patients stay alert so they can perform at their best}

Seldane ${ }^{\circledR}$ (terfenadine) $60 \mathrm{mg}$ Tablets

CAUTION: Federal law prohibits dispensing without prescription.

DESCRIPTION

Seldane (terfenadine) is available as tablets for oral administration. Each tablet contains $60 \mathrm{mg}$ terfenadine. Tablets also contain, as inactive ingredients: corn starch, gelatin, lactose, magnesium stearate, and sodium bicarbonate.

INDICATIONS AND USAGE Seldane is indicated for the relief of symptoms

CONTRAiNDICATIONS

CONTRAINDICATIONS
Seldane is contraindicated in patients with a known hypersensitivity to terfenadine or any of its ingreSeldane is
dients.

PRECAUTIONS

Information for patients

Patients taking Seldane should receive the following information and instructions. Antihistamines are prescribed to reduce allergic symptoms. Patients should be questioned about pregnancy or lactation before starting Seldane therapy, since the drug should be used in pregnancy or lactation only if the potential benefit justifies the potential risk to fetus or baby. Patients should be instructed to take Seldane only as needed and not to exceed the prescribed dose. Patients should also be instructed to store this medication in a tightly closed container in a cool, dry place, away from heat or direct sunlight, and away from children.

Carcinogenesis, mutagenesis, impairment of fertility

Oral doses of terfenadine, corresponding to 63 times the recommended human daily dose, in mice for 18 months or in rats for 24 months, revealed no evidence of tumorigenicity. Microbial and micronucleus test assays with terfenadine have revealed no evidence of mutagenesis.

Reproduction and fertility studies in rats showed no effects on male or female fertility at oral doses of up to 21 times the human daily dose. At 63 times the human daily dose there was a small but significant reduction in implants and at 125 times the human daily dose reduced implants and increased post-implantation losses were observed, which were judged to be secondary to maternal toxicity. Pregnancy Category C

There was no evidence of animal teratogenicity. Reproduction studies have been performed in rats at doses 63 times and 125 times the human daily dose and have revealed decreased pup weight gain and survival when tertenadine was administered throughout pregnancy and lactation. There are no adequate and well-controlled studies in pregnant women. Seldane should be used during pregnancy only it the potential benefit justifies the potential risk to the fetus.

Nonteratogenic effects

Seldane is not recommended for nursing women. The drug has caused decreased pup weight gain and survival in rats given doses 63 times and 125 times the human daily dose throughout prennancy and lactation. Effects on pups exposed to Seldane only during lactation are not known, and there are no adequate and well-controlled studies in women during lactation.

Pediatric use

Safety and effectiveness of Seldane in children below the age of 12 years have not been established

General

Consideration should be given to potential anticholinergic (drying) effects in patients with lower airway disease, including asthma.

ADVERSE REACTIONS

Experience from clinical studies, including both controlled and uncontrolled studies involving more than 2,400 patients who received Seidane, provides information on adverse experience incidence for periods of a few days up to six months. The usual dose in these studies was $60 \mathrm{mg}$ twice daily, but in a small number of patients, the dose was as low as $20 \mathrm{mg}$ twice a day, or as high as $600 \mathrm{mg}$ daily.

In controlled clinical studies using the recommended dose of $60 \mathrm{mg} \mathrm{b.i.d.,} \mathrm{the} \mathrm{incidence} \mathrm{of} \mathrm{reported}$ adverse effects in patients receiving Seldane was similar to that reported in patients receiving placebo. (See Table below.)

ADVERSE EVENTS REPORTED IN CLINICAL TRIALS

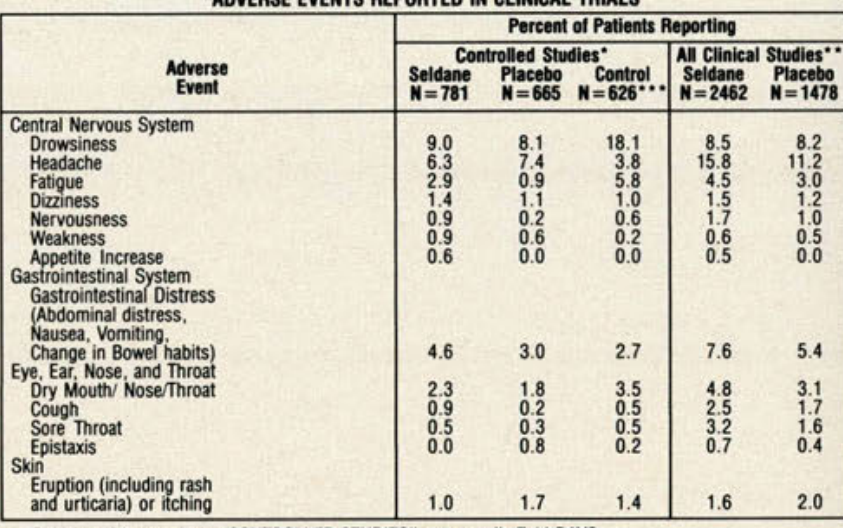

"Duration of treatment in "CONTROLLED STUDIES" was usually 7-14 DAYS.

-Duration of treatment in "ALL CLINICAL STUDIES" was up to 6 months. CONTROL DI

In addition to the more frequent side effects reported in clinical trials (See Table), adverse effects have been reported at a lower incidence in clinical trials and/or spontaneously during marketing of Seldane that warrant listing as possibly associated with drug administration. These include: alopecia, (hair los oring chos ys onged ar interval, seizures, sweating, syncope, tachycardia, tremor, urinary requency, and visua

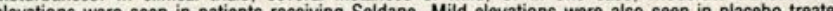
evations warke seen in patients recelving seldane. Mild elevations were also seen in placebo treated .

OVERDOSAGE

Information concerning possible overdosage and its treatment appears in Full Prescribing Information DOSAGE AND ADMINISTRATION

The usual dosage for adults and children 12 years and older is $60 \mathrm{mg}$ (1 tablet) twice daily.

Product Information as of June, 1988

MERRELL DOW PHARMACEUTICALS INC

Subsidiary of The Dow Chemical Company

Cincinnati, Ohio 45215, U.S.A

Merrell Dow

PRINTED IN USA

trial of terfenadine in seasonal allergic rhinitis and conjunctivitis. Ann Allergy 1985:54:502-509 2. Backhouse CI. Brewster BS, Lockhart JDF et al: Terfenadine in allergic rhinitis. A comparative trial of a new antihistamine versus chlorpheniramine and placebo. Practitioner 1982:226:347-348, 351. 3. Buckley CE. Buchman E. Falliers CJ, et al: Terfenadine treatment of fall hay fever. Ann Allergy 1988;60:123-128. 4. Melillo G. D'Amato G. Zanussi C. et al: A multicentre controlled trial of terfenadine, dexchlorpheniramine, and placebo in allergic rhinitis. Arzneim-Forsch/Drug Res 1982:32:1202-1203. 5. Data on file, MERRELL DOW PHARMACEUTICALS INC. Cincinnati, Ohio 45215. 6. MurphyO'Connor JC. Renton RL. Westlake DM: Comparative trial of two dose regimens of terfenadine in patients with hay fever. J Int Med Res 1984:12:333-337. 7. Hüther KJ. Renftle G. Barraud N, et al: Inhibitory activity of terfenadine in histamine-induced skin wheals in man. Eur J Clin Pharmacol 1977:12:195-199. 8. Kemp JP, Falliers Cj. Fox RW, et al: A multicenter, open study of the non-sedating antihistamine, terfenadine (Seldane ${ }^{6}$ ), in the maintenance therapy of seasonal allergic rhinitis. Ann Allergy 1988:60:349-354. 9. Krause LB, Shuster S: The effect of terfenadine on dermographic wealing. Br J Dermatol 1984:10:73-79. 10. Simons FR, Watson WT. Simons KJ: Lack of subsensitivity to terfenadine during long-term treatment. J Allergy Clin Immunol 1988:82:1068-1075 
diagnosis of acute leukemia of megakaryocyte lineage (M7). A report of the French-American-British Cooperative Group. Ann Intern Med 1985;103:460-462.

16. Bloomfield CD, Brunning RD: The Revised French-AmericanBritish classification of acute myeloid leukemia: Is new better? Ann Intern Med 1985;103:614-616.

17. Pui $\mathrm{CH}$, Williams DL, Scarborough V, et al: Acute megakaryocytic leukemia associated with intrinsic platelet dysfunction and constitutional ring 21 chromosome in a young boy. Br J Haematol 1982;50:191-200.

18. Castro-Malaspina H, Rabellino EM, Yen A, et al: Human megakaryocyte stimulation of proliferation of bone marrow fibroblasts. Blood 1981;57:781-787.

19. Van Slyck EJ, Weiss L, Dully M: Chromosomal evidence for the secondary role of fibroblastic proliferation in acute myelofibrosis. Blood 1970;36:729.

20. Smith JW, Shulman HM, Thomas ED, et al: Bone marrow transplantation for acute myelofibrosis. Cancer 1981;48:21982203.

21. Wolf JL, Spruce WE, Bearman RM, et al: Reversal of acute ("malignant" myelosclerosis by allogeneic bone marrow transplantation. Blood 1982;59:191-193.

22. Mehta AB, Baughan AS, Catovsky D, et al: Reversal of marrow fibrosis in acute megakaryoblastic leukemia after remissioninduction and consolidation chemotherapy followed by bone marrow transplantation. Br J Haematol 1983;53:445-449.

23. Kroener JF, McMillan R, Beutler E: Acute myelofibrosis. JAMA 1983;249:1189-1190.

The work reported herein was performed under the Navy Clinical Investigation Program, case report no. 84-161968-39. The views expressed in this article are those of the author and do not reflect the official policy or position of the Department of the Navy, Department of Defense, nor the U.S. Government. 